\title{
A Comparison of Criminal Sexual Conduct Defendants Based on Victim Age*
}

\begin{abstract}
This study compared defendants charged with Criminal Sexual Conduct whose victims were $<6$ years of age with defendants whose victims were 12 or more years of age. The study included 163 men referred to the evaluation unit of a state center for forensic psychiatry. Thirtyeight men had younger victims (YVs) and 125 men had older victims (OVs). The variables of comparison were defendant demographic and psychiatric variables frequently identified in the sex offender literature. Controlling for other demographic and psychiatric variables by use of logistic regression modeling, elderly defendants (60 years or greater), and incest offenders were three times more likely to have YVs (Odds Ratio [OR] 3.08 and 3.11, respectively). Unlike previous studies defendants with serious psychiatric pathology (psychosis or mania) were no more likely to have YVs (OR 0.66) than were defendants without psychosis.
\end{abstract}

KEYWORDS: forensic psychiatry, sex offender, psychosis, logistic regression, victim age

Despite much rigorous work characterizing the importance of psychiatric co-morbidity in clinical and community populations, the issue of co-morbid psychiatric diagnoses in sex offenders is still understudied (1). A small group (8-30\%) of offenders were found to be entirely free of psychopathology other than meeting criteria for at least one paraphilia (2-5). The most frequently diagnosed disorder for rapists and extra familial molesters was antisocial personality disorder (6) with rates approaching $40 \%$ (7). However, every personality disorder was represented at least once in a study of rapists and child molesters (8). The incidence of psychosis in three separate studies was small (10-15\%) (9-11).

Swedish researchers found high rates of alcohol $(7.8 \%)$ and drug $(2.8 \%)$ use, followed by personality disorders $(1.8 \%)$ and psychosis $(1.4 \%)$ among a large $(n=1215)$ group of convicted sex offenders. However, only offenders requiring psychiatric hospitalization were given a diagnosis (12). Rates of psychiatric diagnoses may vary depending on the type of sexual offense. McElroy et al. (13) found much higher rates of substance use disorder $(83 \%)$ and personality disorders (94\%) among incarcerated sex offenders, compared to a group of outpatient pedophiles $(60 \%$ for both substance use disorder and personality disorders). Similarly Belgian researchers found a strong correlation (0.460) between personality disorders and child molesting (14).

In the state of Michigan, criminal sexual conduct (CSC) encompasses a range of sexual offenses ranked in order of severity from CSC-IV (least severe) to CSC-I (most severe). To qualify as CSC-I, the act must include sexual penetration. CSC-II must include sexual contact. CSC-III includes acts such as consensual sexual penetration with a minor. CSC-IV is a misdemeanor and includes acts such as inappropriate touching by healthcare workers $(15,16)$.

Criminal defendants charged with CSC and referred for courtordered forensic psychiatric evaluations had significant differences

\footnotetext{
${ }^{1}$ Michigan Center for Forensic Psychiatry and University of Michigan Department of Psychiatry, PO Box 2060, Ann Arbor, MI 48106.

${ }^{2}$ School of Business Administration, Oakland University, Rochester, MI 48309 .

*2006 Honorable Mention/Richard Rosner Award for the Best Paper by a Fellow in Forensic Psychiatry or Forensic Psychology.

Received 9 June 2006; and in revised form 18 Mar. 2007; accepted 31 Mar. 2007; published 21 Dec. 2007.
}

in the Diagnostic and Statistical Manual of Mental Disorders, Fourth Edition (DSM-IV) (17) diagnoses compared with defendants charged with other offences. Those charged with sexual offenses had higher rates of mental retardation (11\% vs. $2 \%)$ and paraphilias ( $25 \%$ vs. 2\%), lower rates of mood disorders (5\% vs. 20\%) and psychotic disorders (16\% vs. $32 \%)$, and similar rates of personality disorders $(42 \%$ vs. $42 \%)$ and substance use disorders (42\% vs. 48\%) (18).

Sex offenders who prey on very young victims (YVs) (prepubescent) may demonstrate significantly more psychopathology and emotional disturbance than those with older victims (OVs) $(19,20)$. In Firestone's (20) small sample of incest offenders, he found that men who offended sexually against very young children $(<6$ years old) had more severe psychiatric illnesses than men who offended against older children. He found no difference in the mean age of those who abused children $<6$ years of age (mean of 40.8) and those who abused children between the ages of 12-16 years (mean of 39.5). Variables of interest were not tested in linear or logistic regression models to control for confounding between variables.

We set out to replicate the findings of Firestone (20) with respect to defendant psychopathology and defendant age, using logistic regression modeling to control for other independent variables that may contribute to the variance in the outcome (dependant) variable of victim age. Based on Firestone's (20) work we hypothesized that defendants with very YVs $(<6$ years old) would be more likely to meet criteria for disorders such as psychosis and mania than would defendants with victims 12 years of age or older. We also hypothesized that older defendants would be no more likely than younger defendants to have very YVs.

\section{Methods}

\section{Subjects}

The Research Ethics Committee at the Michigan Center for Forensic Psychiatry (CFP) approved the study design. The Michigan CFP conducts psychiatric evaluations for all of the district and circuit criminal courts in Michigan. Twenty-one doctoral-level psychologists and two psychiatrists staff the Evaluation Unit, 
performing evaluations for competency to stand trial and criminal responsibility. We reviewed the charges of c. 25,000 defendants referred to the Michigan CFP between 1988 and 2001 searching for defendants charged with CSC. Subjects were 38 men charged with First, Second, or Third degree CSC whose youngest victim was <6 years old (YVs). Controls were 125 men charged with First, Second, or Third degree CSC whose youngest victim was 12 years of age or older (OVs).

\section{Procedures}

We developed a retrospective, case-control study examining the demographic profiles and pattern of psychiatric morbidity of defendants referred to the Michigan CFP. In addition to reviewing the evaluation reports to the court, we reviewed police reports and prior medical records when available. We performed coding of data from these sources. Police reports were used primarily to confirm victim demographics and to assist in constructing a time line for the onset of symptoms.

The primary outcome of interest in the present study was victim age. The source for the data concerning victim age was police reports. Subjects were excluded if police reports did not contain the age of the victim. In an attempt to replicate the findings of previous authors $(19,20)$ we divided our victims in two categories: ages $0-5$ years and ages $\geq 13$ years. Independent variables of interest were divided into demographic variables and psychiatric variables.

\section{Defendant Demographics}

Defendants were classified for sociodemographic factors such as age, race, and highest attained education. We examined defendant age as a categorical independent variable with "elderly" defined as age $>60$ years. The source for this information was defendant selfreport confirmed by police reports.

\section{Psychiatric Morbidity}

In addition to reviewing the evaluation letters to the court, we reviewed police reports and prior medical records when available. Psychiatric diagnoses were assigned according to DSM-IV criteria. Defendants meeting criteria (past or present) for schizophrenia, schizophreniform disorder, schizoaffective disorder, delusional disorder, brief psychotic disorder, psychotic disorder not otherwise specified and substance-induced psychotic disorder were all grouped into psychotic disorders. Defendants meeting criteria (past or present) for major depressive disorder and dysthymic disorder were grouped into depressive disorders. Defendants meeting criteria (past or present) for bipolar I disorder, bipolar II disorder and cyclothymic disorder were grouped into bipolar disorders. Disorders with an overall prevalence of lower than $0.5 \%$ were excluded.

\section{Statistical Analysis}

Associations of risk factors with category of victim were first assessed at the bivariate level by testing for statistical significance with a Fisher's exact test (chi square) for categorical variables. Variables of interest are listed in Table 1. Odds ratios (OR) with $95 \%$ confidence intervals $(95 \% \mathrm{CI})$ derived from logistic regression were used to explore associations between demographic and psychiatric independent variables and the dependant variable, victim age. All variables from the bivariate analysis were included in the regression model. Dummy variables were created to compare: white ethnicity to all others and Junior High Education or less to
TABLE 1-Victim age stratified by defendant age.

\begin{tabular}{lcccccc}
\hline & \multicolumn{5}{c}{ Victim age (years) } \\
\cline { 2 - 6 } Defendant age (years) & $0-5$ & $6-11$ & $12-17$ & $18-64$ & $>64$ & Total \\
\hline Elderly(>60) & 19 & 70 & 18 & 14 & 4 & 125 \\
Young (18-49) & 19 & 61 & 41 & 47 & 1 & 169 \\
& & & & & & 294 \\
\hline
\end{tabular}

all other levels of education, Logistic regression was used to test for confounding and interaction of risk factors.

\section{Results}

A complete categorization of victim age by defendant age is presented in Table 1. We found a total of 294 defendants with a known age of victim. Of the 294, there were 38 victims between the ages of 0 and 5 years, 131 victims aged 6-11 years, and 125 victims 12 years and older. Results of the bivariate analysis are presented in Table 2. Fifty-eight of the defendants were charged with assaults considered to be incest. One hundred twenty-eight defendants were charged with assaults against unrelated persons. Significant differences ( 0.05 level) were detected for defendant age and whether the assault was characterized as incest or not.

Twenty-five men $(15.3 \%)$ in our study met criteria for psychosis. We did not find that defendants with serious diagnoses such as psychosis or bipolar disorder were more likely to have YVs. While the majority of defendants with Axis I diagnoses had victims 12 years of age or older, the differences were not significant. Only $12 \%$ of defendants who had at least one episode of psychosis had a victim 5 years or less.

Table 3 contains the results of the logistic regression model. Controlling for other demographic and psychiatric variables, elderly defendants were three times more likely to have YVs than were younger defendants (OR of 3.081). Defendants who were related to their victims were also three times more likely to have YVs (OR of 3.110). Compared to defendants without psychosis, defendants with at least one episode of psychosis were only $66 \%$ as likely to have YVs.

\section{Discussion}

The trend for geriatric defendants to have younger, weaker victims was consistent with the work of previous authors (21). This finding makes sense from a purely physical standpoint. Elderly defendants may have more difficulty physically restraining or overpowering victims over the age of 12 .

The finding that defendants with a history of psychosis were less likely to have YVs contrasted the findings of previous authors who reported that men abusing prepubescent victims had more psychopathology than men with OVs $(19,20)$. The fact that we controlled for confounding across variables by using logistic regression does not completely explain the divergent results. One possible explanation is that our population had a higher baseline of psychopathology since they were referred by the courts for competency and criminal responsibility evaluations. Our rate of psychosis across all subjects $(15.3 \%)$ was nearly identical to the rate of psychosis in a large study of pretrial CSC defendants (16\%) (18) and well within the range $(10-15 \%)$ of three other studies of sex offenders (9-11). A second explanation is that we used a different definition of "severe psychopathology." We define it as meeting DSM-IV criteria for either psychosis or mania, roughly corresponding to Michigan's statutory definition of mental illness: "a substantial disorder 
TABLE 2-Univariate relationships between independent variables and victim status.

\begin{tabular}{|c|c|c|c|c|c|c|c|}
\hline Independent variable & Category & $n^{*}$ & YV & Rate \% & OV & Rate \% & $p$-Value ${ }^{\dagger}$ \\
\hline Eligible sample & & 163 & 38 & & 125 & & \\
\hline \multicolumn{8}{|l|}{ Sociodemographics } \\
\hline \multirow[t]{2}{*}{ Defendant age } & 60 year+ & 65 & 19 & 29.2 & 46 & 70.8 & 0.048 \\
\hline & $<60$ years & 114 & 19 & 16.7 & 95 & 83.3 & \\
\hline \multirow[t]{2}{*}{ Defendant race } & White & 145 & 37 & 25.5 & 108 & 74.5 & 0.122 \\
\hline & Other & 42 & 4 & 9.5 & 35 & 90.5 & \\
\hline \multirow[t]{2}{*}{ Defendant education } & Jr. High Education or less & 44 & 13 & 29.5 & 31 & 70.5 & 0.252 \\
\hline & $>$ Jr. High Education & 119 & 25 & 21.0 & 94 & 79.0 & \\
\hline \multirow[t]{2}{*}{ Incest } & Yes & 58 & 20 & 34.5 & 38 & 65.5 & 0.006 \\
\hline & No & 128 & 21 & 16.4 & 107 & 83.6 & \\
\hline \multicolumn{8}{|l|}{ Psychiatric diagnoses } \\
\hline \multirow[t]{2}{*}{ Psychosis } & Yes & 25 & 3 & 12.0 & 22 & 88.0 & 0.208 \\
\hline & No & 142 & 33 & 23.2 & 109 & 76.8 & \\
\hline \multirow[t]{2}{*}{ Substance abuse ${ }^{\S}$} & Yes & 81 & 17 & 21.0 & 64 & 79.0 & 0.768 \\
\hline & No & 83 & 19 & 22.9 & 64 & 77.1 & \\
\hline \multirow[t]{2}{*}{ Mental retardation } & Yes & 28 & 5 & 17.9 & 23 & 82.1 & 0.634 \\
\hline & No & 137 & 30 & 21.9 & 107 & 78.1 & \\
\hline \multirow{2}{*}{ Unipolar depression } & Yes & 28 & 5 & 17.9 & 23 & 82.1 & 0.602 \\
\hline & No & 139 & 31 & 22.3 & 108 & 77.7 & \\
\hline \multirow[t]{2}{*}{ Bipolar disorder** } & Yes & 5 & 0 & 0 & 5 & 100 & 0.241 \\
\hline & No & 161 & 35 & 21.7 & 126 & 78.3 & \\
\hline
\end{tabular}

YV, younger victim; OV, older victim.

*Numbers for each variable may not add up to 163 due to missing data.

†Pearson chi-square or Fisher's exact test comparing cases with controls.

Includes schizophrenia, schizophreniform disorder, schizoaffective disorder, and psychotic disorder not otherwise specified.

${ }^{\S}$ Includes alcohol and/or nonalcohol abuse or dependence.

Includes major depressive disorder, dysthymia, and depressive disorder not otherwise specified.

**Includes bipolar I and II, and other bipolar disorder.

TABLE 3-Logistic regression model comparing "young victims" (age 0-12 years) with victims aged 13 years and above.*

\begin{tabular}{lcccc}
\hline Independent variable & $p$-Value & $\begin{array}{c}\text { Exp. } \\
\text { beta }\end{array}$ & $\begin{array}{c}95.0 \% \text { CI } \\
\text { lower }\end{array}$ & $\begin{array}{c}\text { For exp. } \\
\text { beta upper }\end{array}$ \\
\hline Elderly defendant & 0.039 & 3.081 & 1.059 & 8.968 \\
White race & 0.326 & 0.505 & 0.130 & 1.971 \\
Jr. High Education or less & 0.794 & 0.867 & 0.298 & 2.521 \\
Incest & 0.023 & 3.110 & 1.172 & 8.251 \\
Diagnosis psychosis & 0.618 & 0.658 & 0.127 & 3.403 \\
Substance abuse & 0.475 & 0.724 & 0.298 & 1.757 \\
Diagnosis mental retardation & 0.858 & 0.889 & 0.243 & 3.245 \\
Diagnosis unipolar depression & 0.119 & 2.774 & 0.769 & 10.015 \\
Diagnosis bipolar depression & 0.999 & $6.19 \mathrm{e}+8$ & 0 &. \\
\hline
\end{tabular}

*The dependant variable is age of victim.

of thought or mood which significantly impairs judgment, behavior, capacity to recognize reality, or ability to cope with the ordinary demands of life" (15). Firestone (20) defined "significant psychiatric disturbance" as "higher scores on the Brief Psychiatric Rating Scale." He opined that one reason for the significant psychopathology in his YV offender group might be that all subjects were incest offenders. Our findings controlled for incest (by forcing incest as an independent variable in the regression model), and still found no significant differences between psychotic and nonpsychotic defendants.

Our finding that persons with psychosis were less likely to have very YVs makes sense from a purely opportunistic viewpoint. It seems unlikely that parents would leave children under 6 years of age alone with a male who has a history of being psychotic.

Potential limitations in our study included using clinical interviews to assign diagnoses rather than use of an interview and structured instruments. Structured interviews would have been preferred. In their absence, lines of evidence point to the reliability of clinical impression of experienced evaluators approaching the reliability of structured interviews in certain populations (22). A second potential limitation involves the use of retrospective chart reviews. These reviews may include difficulty in validating the data, in controlling extraneous variables and missing data. One is limited to the data that exists and one has less ability to manipulate variables of interest. For the study of rare conditions such as sex offenders in psychiatric settings, retrospective case control designs may provide the best means of obtaining a critical mass of cases.

Our conclusions refer specifically to CSC defendants referred for competency and criminal responsibility evaluations. A population of defendants referred for psychiatric evaluation may not be representative of all persons who commit CSC. To the best of our knowledge, however, this is the first study that attempts to describe the characteristics of defendants charged with CSC and referred for competency and criminal responsibility evaluations in a systematic controlled fashion. Interested parties may include psychiatrists, psychologists and social workers who evaluate and treat sex offenders. Our findings may well provide an initial view into the characteristics of the larger population of sex offenders. These findings are preliminary in nature. Future studies should involve a larger sample size with a prospective design.

\section{References}

1. Kafka M. The monoamine hypothesis for the pathophysiology of paraphilic disorders: an update. Ann N Y Acad Sci 2003;1989:86-94.

2. Apfelberg B, Sugar C, Pfefer A. A psychiatric study of 250 sex offenders. Am J Psychiatry 1944;100:762-9.

3. Brancale R, Ellis A, Doorbar R. Psychiatric and psychological investigations of convicted sex offenders: a summary report. Am J Psychiatry 1952;109:17-21.

4. Brancale R, MacNeil D, Vuocolo A. Profile of the New Jersey sex offender: a statistical study of 1206 male sex offenders. Welfare Rep 1965;16:3-9.

5. Frossch J, Bromberg W. The sex offender: a psychiatric study. Am J Orthopsychiatry 1939;9:761-76. 
6. Prentky R, Burgess A, editors. Forensic management of sexual offenders. New York, New York: Kluwer Academic/Plenum Publishers, 2000;28-30.

7. Motiuk L, Porporino F. The prevalence, nature, and severity of mental health problems among federal male inmates in Canadian penitentiaries (Report No. 24). Ottawa, Canada: Correctional Services of Canada, 1992.

8. Schneider B.Validation of sex offender subtypes through personality assessment. In: Prentkey R, editor. Assessment of subtypes of rapists and pedophiles: implications for treatment. Proceedings of Annual Symposium of American Psychological Association, Aug 24-28, 1981, Los Angeles, CA. Washington, DC: American Psychological Association, 1981.

9. Gebhard P, Gagnon J, Pomeroy W, Christenson C. Sex offenders: an analysis of types. New York: Harper and Rowe, 1965.

10. Rada R. Clinical aspects of the rapist. New York: Grune and Stratton, 1978.

11. Prentky R. The neurochemistry and neuroendocrinology of sexual aggression: review and metatheory. In: Farrington D, Gunn J, editors. Aggression and dangerousness. New York: Wiley, 1985;7-55.

12. Langstrom N, Sjostedt G, Grann M. Psychiatric disorders and recidivism in sexual offenders. Sex Abuse 2004;16:139-50.

13. McElroy SL, Soutullo CA, Taylor P, Nelson EB, Beckman DA, Brusman LA, et al. Psychiatric features of 36 men convicted of sexual offences. J Clin Psychiatry 1999;60:414-20.

14. Bogaerts S, Vervaeke G, Goethals J. A comparison of relational attitude and personality disorders in the explanation of child molestation. Sex Abuse 2004;16:37-47.

15. Michigan Compiled Laws. MCL Sec 750.520. 2006.
16. Michigan Compiled Laws MCL section 330.1400a. 2006.

17. American Psychiatric Association. Diagnostic and statistical manual of mental disorders. 4th ed. Washington, DC: American Psychiatric Association Publishing, 1994.

18. Cochrane RE, Grisso T, Frederick RI. The relationship between criminal charges, diagnoses and psycholegal opinions among federal pretrial defendants. Behav Sci Law 2001;19:565-82.

19. Kalichman SC. Psychopathology and personality characteristics of criminal sex offenders as a function of victim age. Arch Sex Behav 1991;20:187-97.

20. Firestone P, Dixon KL, Nunes KL, Bradford JM. A comparison of incest offenders based on victim age. J Am Academy Psychiatry Law 2005;33:223-32.

21. Blanchard R, Barbaree H, Bogaert A, Dickey R, Klassen P, Kuban M, Zucker K. Fraternal birth order and sexual orientation of pedophiles. Arch Sex Behav 2000;29:463-78.

22. Neighbors HW, Trierweiler SJ, Ford BC, Muroff JR. Racial differences in DSM diagnosis using a semi-structured instrument: the importance of clinical judgment in the diagnosis of African-Americans. J Health Soc Behav 2003;44(3):237-56.

Additional information and reprint requests:

Ernest Poortinga, M.D., M.S.

Michigan Center for Forensic Psychiatry and University of Michigan Department of Psychiatry

PO Box 2060

Ann Arbor, MI 48106

E-mail:poortingae@michigan.gov 